\title{
Preparation of Paper Mulberry Fibers and Possibility of Cotton/Paper Mulberry Yarns Production
}

\author{
Manoon Jitjaicham ${ }^{1}$ and Boonsri Kusuktham ${ }^{2}$ \\ ${ }^{1}$ Division of Textile Engineering, Faculty of Textile Industries, Rajamangala University of Technology Krungthep, \\ Bangkok 10120, Thailand \\ ${ }^{2}$ Division of Textile Chemical Engineering, Faculty of Textile Industries, Rajamangala University of Technology Krungthep, \\ Bangkok 10120, Thailand
}

Correspondence should be addressed to Boonsri Kusuktham; kuboonsri@yahoo.com

Received 15 March 2016; Accepted 25 July 2016

Academic Editor: Kaustubha Mohanty

Copyright (C) 2016 M. Jitjaicham and B. Kusuktham. This is an open access article distributed under the Creative Commons Attribution License, which permits unrestricted use, distribution, and reproduction in any medium, provided the original work is properly cited.

\begin{abstract}
The novelty of yarn production from cotton/paper mulberry fiber blends was reported. The objective of this research was to prepare the paper mulberry fibers and study the possibility of production of yarns from cotton/paper mulberry fibers. For preparation of paper mulberry fibers, the inner bark was first immersed in water for $24 \mathrm{~h}$. Then, the fibers were treated with sodium hydroxide at concentration of $5-10 \%(\mathrm{w} / \mathrm{v})$ for $1-3 \mathrm{~h}$. After that, the bleaching process was conducted with hydrogen peroxide at concentration of $5-25 \%(\mathrm{v} / \mathrm{v})$ for different temperature and time. Finally, the fibers were washed with $10 \%(\mathrm{v} / \mathrm{v})$ of nonionic surfactant at temperature of $90^{\circ} \mathrm{C}$ for 30 minute to remove the residual gum from the fibers. The results showed that optimum condition for scouring of the paper mulberry fibers was $15 \%(\mathrm{w} / \mathrm{v})$ sodium hydroxide at $90^{\circ} \mathrm{C}$ for $2 \mathrm{~h}$. The bleaching process with $15 \%(\mathrm{v} / \mathrm{v}) \mathrm{H}_{2} \mathrm{O}_{2}$ at $90^{\circ} \mathrm{C}$ for 90 minute was suitable. The obtained fibers were blended with the cotton fibers to produce yarns by open-end spinning method. The \% elongation and tenacity of the blended yarns increased with the increasing of the paper mulberry ratio. Also, the antifungal property of yarns was improved by the blending of cotton fibers with the paper mulberry fibers.
\end{abstract}

\section{Introduction}

Natural cellulosic fibers are produced from various sources of plant such as bast, seed, and leaf. These cellulosic fibers are jute, flax, ramie, cotton, and sisal. The use of these fibers is different; for example, cotton is used for apparel, jute for packing, ramie for fabrics and ropes, sisal for rope, and flax for linen. Some of them like cotton and ramie are strong and fine with high length to breadth aspect ratio for good spinnability into yarn for fabric [1]. The production of yarns from the other plants is very interesting. The plant fibers offer several advantages including low density, low cost, biodegradability, and renewable nature.

Paper mulberry is a tree in the family Moraceae [2]. The plant stalks of the paper mulberry are composed of bark and woody xylem [3]. After peeling off the outer bark, many fibers appear. The components of paper mulberry fibers are similar to cotton fibers, such as cellulose, hemicelluloses, lignin, and wax. Unlike cotton fibers, the paper mulberry fibers are composed of gum. The fibers were separated from the outer bark by boiling the bark in an alkali solution such as soda ash or caustic soda to dissolve the lignin, wax, and gums [4]. Fibers that are high in lignin are generally brown color. This is the characteristic of the paper mulberry fibers. Hence, the next step for preparation of the paper mulberry fibers is bleaching process. The purpose of this step is to whiten the fibers. The major bleaching agents used in preparation of the paper mulberry fibers are sodium hypochlorite or calcium hypochlorite [5]. Also, chlorine dioxide was used in the studies of Lin et al. [6]. The derivative of chlorine was claimed to be toxic chemical and related to the greenhouse effect [5]. To reduce the environmental impact, hydrogen peroxide is considered to be used instead of chlorine.

The inner bark of the paper mulberry is composed of very strong fibers and can be used for making high quality paper. The production of paper mulberry paper can be seen 
in Thai village. In Chiang Mai, Thailand, the paper mulberry is manufactured into a wide variety of products for the booming tourist industry [7]. The paper-making from the paper mulberry fibers has been made by hand. The bark is first boiled to soften the fiber and soak overnight at room temperature. Then, the fibers are washed many times. After that, the pulp is placed in the large container to dissipate onto a bamboo frame with a cotton screen. The frame is immersed in the same container and small fibers are captured on the screen. The paper itself forms naturally on the frames, which are placed in the sun to dry, before being peeled from the screens in sheets. Also, this bark was widely used to make tapa cloth in Polynesian culture. To make tapa, the bark was peeled from the cut stems to obtain a single long strip. The inner bark or bark was then separated from the outer bark and after being scraped and washed, the strips were pounded to flatten them. The resulting sheets were felted together to form tapa [8]. Opoku-Asare and Yeboah studied exploring the possibility of recycling waste fabrics into good quality paper. For making paper, the waste fabrics such as linen, nylon, acetate, cotton, polyester, and wool were mixed with the paper mulberry fibers [4].

For using these fibers in textiles, the extraction of the fibers from the inner bark is very important. Also, the extracted fibers will be spun into yarns. The quality of the fibers has an effect on the mechanical properties of the produced yarns.

The present study was carried out in order to prepare the paper mulberry fibers and to produce cotton/paper mulberry yarns. The paper mulberry fibers were extracted from the inner bark with sodium hydroxide solution. The obtained fibers were bleached with hydrogen peroxide. The whiteness index and morphology of the fibers were examined. Also, the yarns were produced by open-end spinning method. The mechanical and antifungal properties of the yarns were investigated.

\section{Experimental}

2.1. Materials. The hydrogen peroxide $(50 \% \mathrm{v} / \mathrm{v})$ was purchased from Star Tech Chemical Industrial Co., Ltd., and used as received. The inner barks of paper mulberry (PM) were purchased from Chiang Mai province, Thailand. The scoured and bleached cotton fibers were obtained from Kongkiat Textile Co., Ltd. Nonionic surfactant (aliphatic esters and fatty alcohol) was purchased from Star Tech Chemical Industrial Co., Ltd.

2.2. Preparation of the Paper Mulberry Fibers. The inner barks of paper mulberry (PM) fibers were immersed in water for $24 \mathrm{~h}$. Then, the PM fibers were placed in solution of $\mathrm{NaOH}$ $(5-20 \%, w / v)$ at $90^{\circ} \mathrm{C}$ for $1-3 \mathrm{~h}$. After alkaline cooking, the PM fibers were washed by distilled water and then air-dried.

2.3. Bleaching of the Paper Mulberry Fibers. Fibers bleaching processes involved variable of $\mathrm{H}_{2} \mathrm{O}_{2}$ concentration (5-25\%, $\mathrm{v} / \mathrm{v})$, variable of temperature $\left(70-90^{\circ} \mathrm{C}\right)$, and bleaching time (10-120 minutes). The effect of temperature on the bleaching was studied at 70,80 , and $90^{\circ} \mathrm{C}$, at $\mathrm{H}_{2} \mathrm{O}_{2}$ concentration $10 \% \mathrm{v} / \mathrm{v}$. After the bleaching process, the fibers were washed with $10 \%(\mathrm{v} / \mathrm{v})$ nonionic surfactant at $90^{\circ} \mathrm{C}$ for 30 minutes to remove the residual gum in the fibers.

\subsection{Characterization of Paper Mulberry Fibers}

2.4.1. The Chemical Compositions of the Paper Mulberry Fibers. The hemicellulose and lignin contents of the PM fibers were tested according to standard TAPPI method (TAPPI T203 cm-99 and TAPPI T222 om-06).

2.4.2. Morphology. The morphological structures of the PM fibers before and after pretreatment were observed by JEOL JSM-5410LV Scanning Electron Microscope.

2.4.3. FTIR Measurement. Infrared spectra of the PM fibers before and after pretreatment were recorded using PerkinElmer FTIR Spectrophotometer System 2000.

2.4.4. Quality of the Paper Mulberry Fibers. The uniformity index of PM fibers was tested with Vibromat single fiber fineness (Vibromat ME, Textechno). The micronaire was measured with the Micronaire, Keisokki. Also, the short fiber index was measured with classifiber sampler and measuring (Classifiber, Keisokki).

2.4.5. Whiteness Measurements. The bleaching effectiveness was evaluated by measuring the whiteness index (WI) of the fiber samples with a spectrophotometer Datacolor 900 using $\mathrm{D}_{65}$ illuminant and $10^{\circ}$ observer. Each sample was folded twice to give an opaque sample.

2.4.6. Production of Yarns. Cotton fibers and PM fibers were mixed together with mixing ratios $90: 10$ and $80: 20$. Then, the machines required to process yarn were carding, drawing, roving, and open-end spinning. Also, the mechanical properties of yarn were tested under Uster Tensojet.

2.4.7. Antifungal Studied. The assay used for measuring antibacterial properties was based on "AATCC Test Method, 30-1989 Antifungal Activity: Assessment on Textile Material: Midew and Rot Resistance of Textile." The antimicrobial activity of the cotton fibers, paper mulberry fibers, and the cotton/paper mulberry yarns was evaluated. The observed growth of Aspergillus niger was evaluated in Table 1.

\section{Results and Discussion}

3.1. Scouring of Paper Mulberry Fibers. Scouring process was conducted to remove many impurities, for example, hemicelluloses, lignins, waxes, and other impurities from the PM fibers. The results of alkaline scouring on the hemicellulose and lignin contents of the PM fibers are shown in Figures 1 and 2, respectively. The results showed that the hemicelluloses and lignin decreased with increasing the concentration of $\mathrm{NaOH}$ and constant at about $15 \%(\mathrm{w} / \mathrm{v}) \mathrm{NaOH}$ for $2 \mathrm{~h}$. 
TABLE 1

\begin{tabular}{lc}
\hline Observed growth & Grade \\
\hline None & 0 \\
Growth only apparent under microscope & 1 \\
Growth visible to the naked eye & \\
Trace (less than 10\%) & 2 \\
Light growth (10-30\%) & 3 \\
Medium growth (30-60\%) & 4 \\
Heavy growth (more than 60\%) & 5 \\
\hline
\end{tabular}

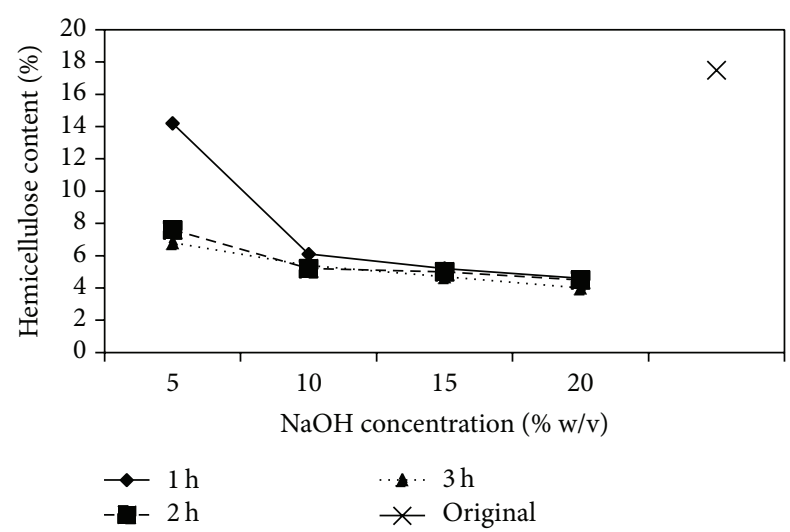

Figure 1: Hemicellulose content in paper mulberry fiber before and after scouring at various $\mathrm{NaOH}$ concentration and time.

The role of $\mathrm{NaOH}$ solution in scouring process was to swell the fibers, dissolve the impurities, and saponify oil and waxes [9]. Thus, the impurities were removed. From these results, the suitable condition for scouring the PM fibers was $15 \%(\mathrm{w} / \mathrm{v}) \mathrm{NaOH}$ at $90^{\circ} \mathrm{C}$ for $2 \mathrm{~h}$.

3.2. Bleaching of Paper Mulberry Fibers. Natural fibers are off-white in color due to color bodies present in the fibers. The conventional bleaching is a process that is used in textiles to improve the whiteness of the materials. The natural coloring of PM fibers is dark brown color. The objective of the bleaching process was to destroy these color bodies. Hydrogen peroxide was used as the bleaching agent in this research.

3.2.1. Effect of Temperature on Bleaching Rate. The result on the whiteness index of the bleached fibers is shown in Figure 3. The result showed that the whiteness index increased as the temperature increased. In general, hydrogen peroxide could decompose to produce hydroxyl radical $\left(\mathrm{HO}^{\circ}\right)$ and superoxide radical $\left(\mathrm{O}_{2}{ }^{--}\right)$[10]. These radicals might react with each other and give hydroxyl anions $\left(\mathrm{OH}^{-}\right)$, as shown in the following [11]:

$$
\mathrm{HO}^{\bullet}+\mathrm{O}_{2}^{\cdot} \longrightarrow \mathrm{O}_{2}+\mathrm{OH}^{-}
$$

The $\mathrm{OH}^{-}$accelerated the decomposition of $\mathrm{H}_{2} \mathrm{O}_{2}$ as shown below [12]:

$$
\mathrm{H}_{2} \mathrm{O}_{2}+\mathrm{OH}^{-} \longrightarrow \mathrm{HOO}^{-}+\mathrm{H}_{2} \mathrm{O}
$$

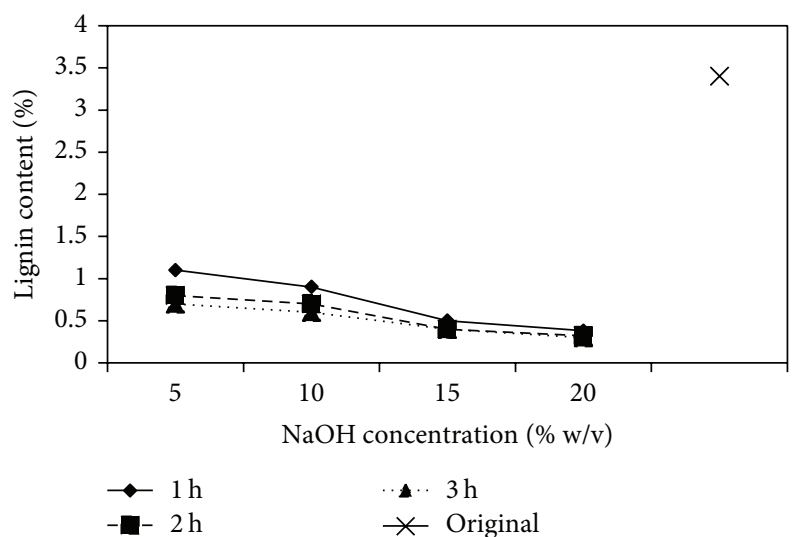

FIGURE 2: Lignin content in paper mulberry fiber before and after scouring at various $\mathrm{NaOH}$ concentration and time.

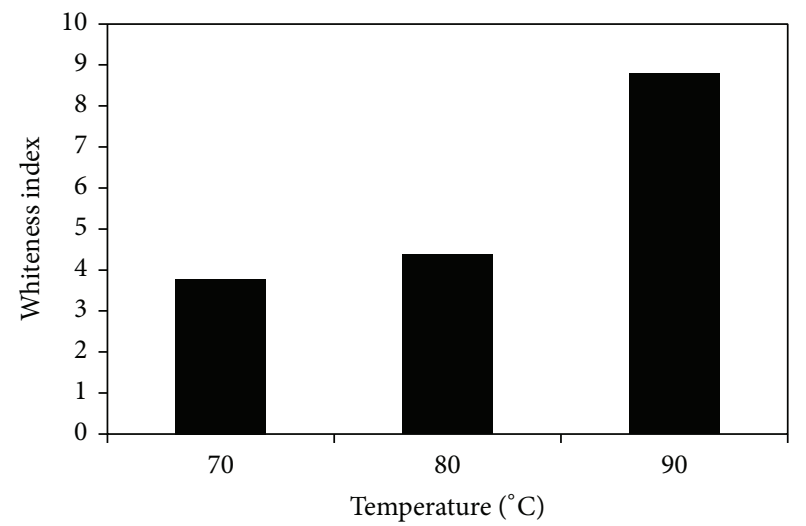

FIGURE 3: Whiteness index of the bleached paper mulberry fibers $\left(10 \% \mathrm{H}_{2} \mathrm{O}_{2}\right.$ at 90 minutes) at various temperature.

The decomposition products caused the oxidation of lignin structure and led to the cleavage of some interunit bonds and the dissolution of lignin and hemicelluloses [10]. In addition, during bleaching, the chromophores were converted to nonchromophoric species [11, 13]. This resulted in increasing the whiteness of the bleached PM fibers. As the bleaching temperature increased, the whiteness increased. This is caused by the increasing of the decomposition of $\mathrm{H}_{2} \mathrm{O}_{2}$ and the oxidation reaction of the PM fibers. Therefore, the temperature had an effect on the bleaching of the PM fibers.

3.2.2. Effect of Hydrogen Peroxide Concentration and Reaction Time of Bleaching. Figure 4 shows the effects of hydrogen peroxide concentration and time of bleaching on the whiteness index of the PM fibers. The result showed that the whiteness index increased with increasing the concentration of $\mathrm{H}_{2} \mathrm{O}_{2}$ and constant at $15 \% \mathrm{H}_{2} \mathrm{O}_{2}$ for 90 minutes. With increasing the $\mathrm{H}_{2} \mathrm{O}_{2}$ concentration the oxidation reaction between the PM fibers and $\mathrm{H}_{2} \mathrm{O}_{2}$ tended to increase. This led to the destruction of color in the fibers.

Figure 5 shows the FTIR spectra of the original PM fibers, scoured and bleached fibers. In the FTIR spectrum of the original PM fibers (see Figure 5(a)), the absorption 


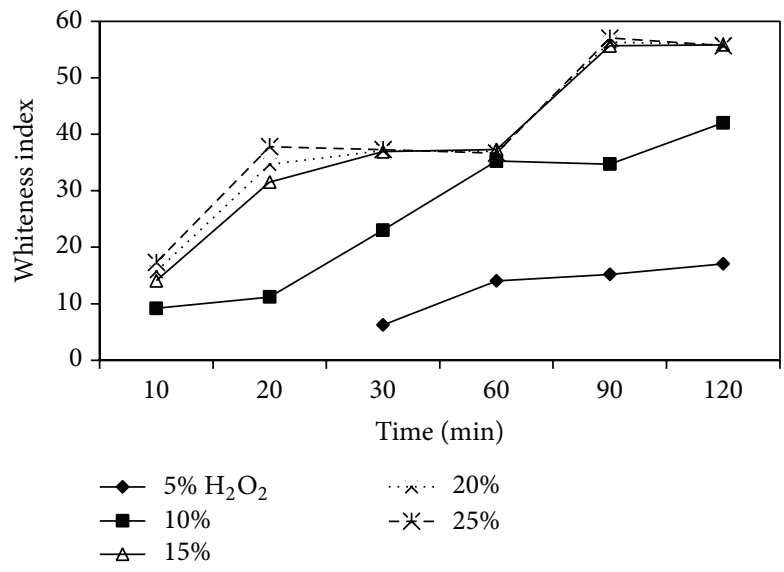

FIGURE 4: Whiteness index of the bleached paper mulberry fibers at various $\mathrm{H}_{2} \mathrm{O}_{2}$ concentrations and time.

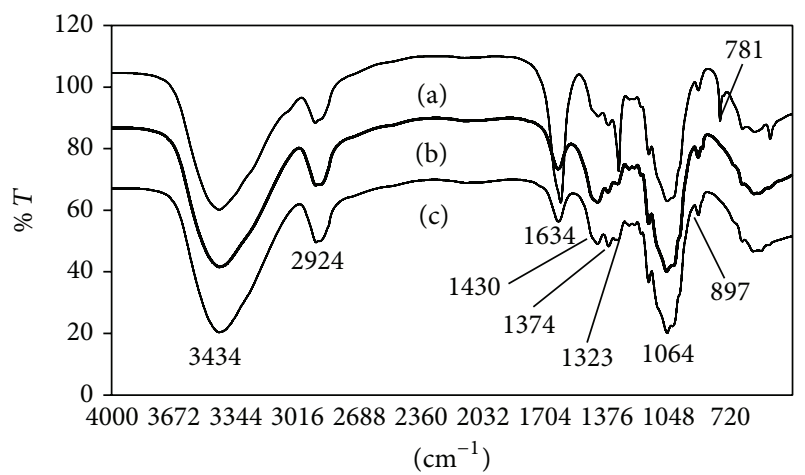

FIGURE 5: FTIR spectra of original paper mulberry fibers (a), scoured paper mulberry fibers (b), and bleached paper mulberry fibers (c).

band at $3434 \mathrm{~cm}^{-1}$ was attributed to the absorbance of -OH functional groups of cellulose and at $2924 \mathrm{~cm}^{-1}$ was due to $-\mathrm{CH}_{2}$ - groups. Also, it showed the spectrum of hemicellulose. In general, hemicellulose was composed of various type of sugars; at $1000-1300 \mathrm{~cm}^{-1}$ it was typical of xylan. The peak at 1318 was attributed to $-\mathrm{CH}_{2}$ blending [10]. In this spectrum, it showed the spectrum of lignin, vibration of aromatic ring of lignin at $1513 \mathrm{~cm}^{-1}$, at 1368 was attributed to $\mathrm{OH}$ in-plane bending [14].

In the spectrum of the scoured PM fibers (see Figure 5(b)), the absorption peaks between 1000 and $1700 \mathrm{~cm}^{-1}$ were changed. The absence of the peak at $1318 \mathrm{~cm}^{-1}$ implied that hemicellulose was removed. In addition, the characteristic peaks of lignin at $1625 \mathrm{~cm}^{-1}$ decreased. This might be due to the removal of lignin in scouring process.

In the spectrum of the bleached PM fibers (see Figure 5(c)), the intensity peak of $-\mathrm{C}=\mathrm{O}$ at $1634 \mathrm{~cm}^{-1}$ decreased. This indicated that some impurities were removed from the fibers. In addition, it showed the absorption spectrum of cellulose, the bending of C-H at 1430, 1374, and $1323 \mathrm{~cm}^{-1}$, and also stretching of C-O-C at 1159, 1064, and $897 \mathrm{~cm}^{-1}$. After the bleaching process, the gum in the fibers was
TABLE 2: Quality parameters of paper mulberry fibers.

\begin{tabular}{lc}
\hline Quality parameters & Data \\
\hline Uniformity index & $61.3 \%$ \\
Micronair & 7.36 micronair \\
Short fiber index & $9.6 \%$ \\
\hline
\end{tabular}

TABLE 3: Mechanical properties of yarn.

\begin{tabular}{lcc}
\hline $\begin{array}{l}\text { Cotton : PM fibers } \\
\text { ratio (by weight) }\end{array}$ & \% elongation & Tenacity (cN/Tex) \\
\hline $90: 10$ & 6.07 & 12.03 \\
$80: 20$ & 6.76 & 12.76 \\
\hline
\end{tabular}

removed with nonionic surfactant resulting in increasing the softness of the PM fibers and leading to the possibility of carding process.

3.3. Morphologies of Paper Mulberry Fibers. The SEM micrographs of the original, scoured, and bleached PM fibers are presented in Figure 6. It appeared that the coating materials on the surface of the original PM fiber were removed in the scouring and bleaching processes. Also, the cross section of the PM fiber showed sheath-core structure as shown in Figure 6(e).

3.4. Quality of Paper Mulberry Fibers. The quality parameters of the PM fibers are shown in Table 2. Uniformity index contributes significantly towards hair severity. From this result, the PM fibers had a good uniformity. This indicated that the fiber length of the PM fibers was uniform.

Fiber fineness is considered as the most important parameter impacting the yarn quality. The result showed that the PM fibers were the coarse fibers.

Short fiber content was an indication of fiber quality: defined as a percentage of fibers less than $12.7 \mathrm{~mm}$. Raw material with higher short fibers content was inferior as it led to high waste $\%$ in the process and yarn produced from this fibers had low strength, more unevenness, and high hairiness [15]. From Table 2, it is shown that the PM fibers had the short fiber index about $9.6 \%$. This indicated that it was possible to produce yarns from the PM fibers mixed with cotton fibers.

3.5. The Yarns Production from Cotton/Paper Mulberry Fibers Blended. In general, the PM fibers have sticky materials in the fibers unlike cotton fibers. Hence, yarn production from 100\% PM fibers was not produced due to the attachment of the PM fibers on the carding machine. In this research, the yarns from cotton/PM fibers blended were produced with openend spinning. The sliver and open-end spinning machine are shown in Figures 7 and 8, respectively. The production of yarns from cotton/PM fibers was possible. The mechanical and antifungal properties of yarns are shown in Tables 3 and 4 , respectively. The mechanical properties of the produced yarns indicated that these yarns would be used in textile application. Also, the PM fibers improved the antifungal property of yarns. 


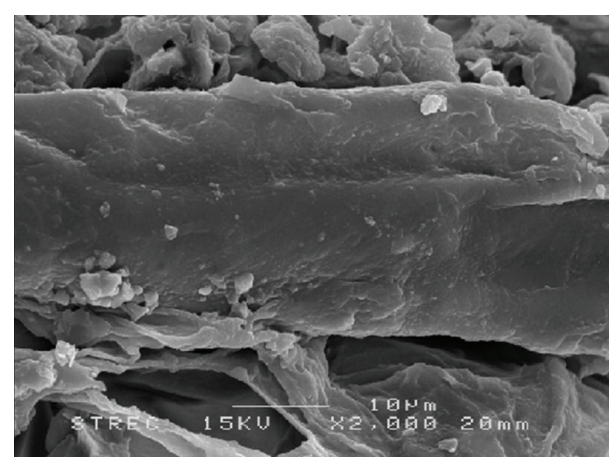

(a)

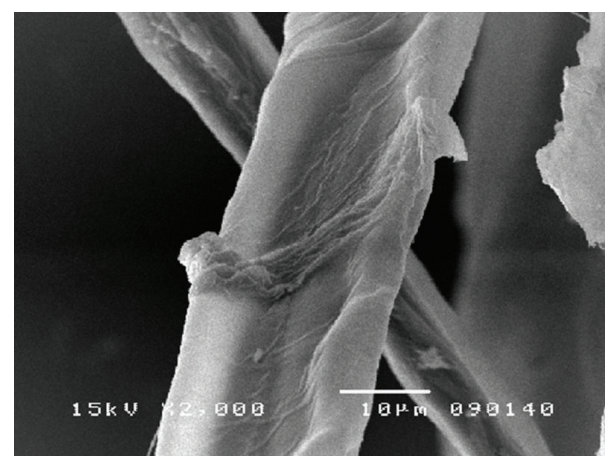

(c)

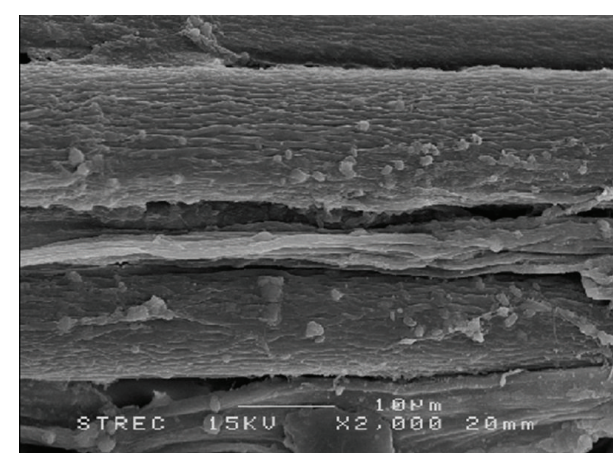

(b)

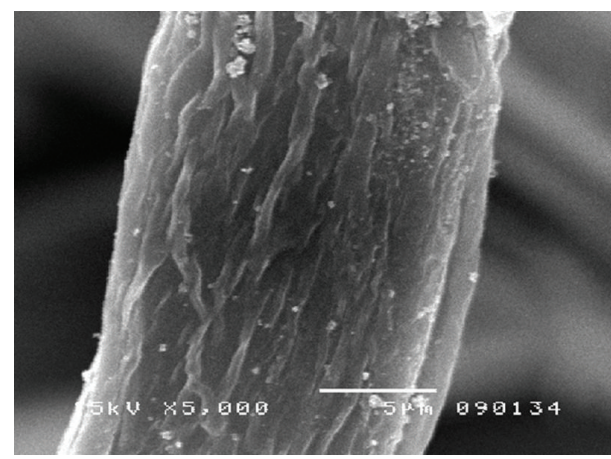

(d)

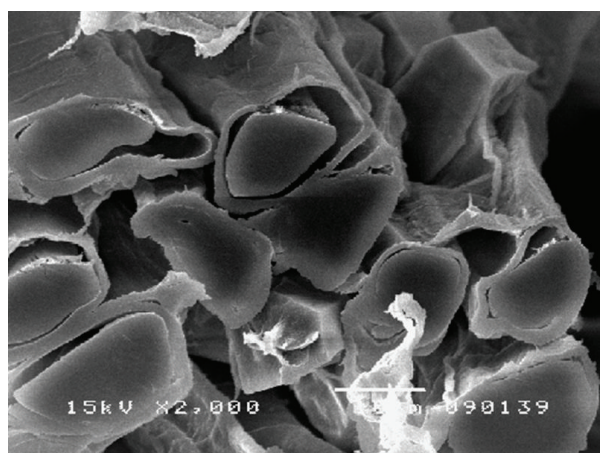

(e)

FIGURE 6: SEM micrographs of original paper mulberry fibers (a), scoured paper mulberry fibers with $15 \%$ (w/v) NaOH solution for $2 \mathrm{~h}$ (b), scoured and bleached paper mulberry fibers with $15 \%(\mathrm{v} / \mathrm{v}) \mathrm{H}_{2} \mathrm{O}_{2}$ for 90 minutes (c-d), and cross section of paper mulberry fibers (e).

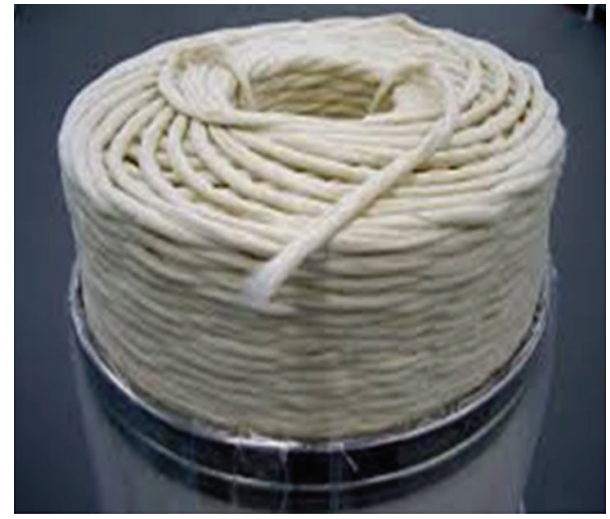

FIGURE 7: Sliver of cotton/paper mulberry fiber blends.

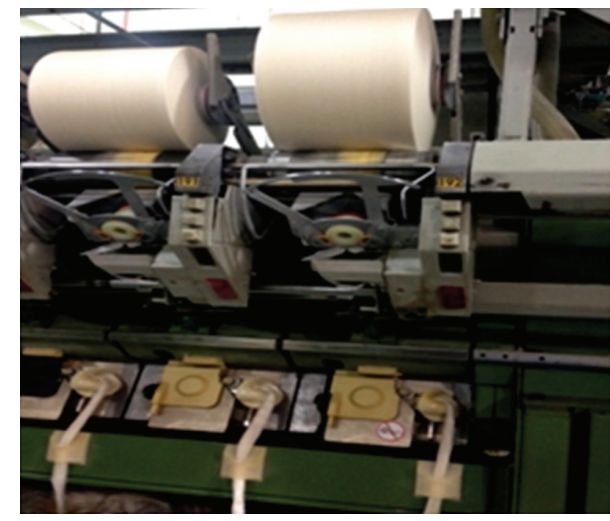

FIGURE 8: Spinning of cotton/paper mulberry yarns. 
TABLE 4: Antifungal property of cotton fibers, paper mulberry fibers, and cotton/paper mulberry yarns.

\begin{tabular}{lcc}
\hline Materials & $\begin{array}{c}\text { Observed fungal } \\
\text { growth }\end{array}$ & Grade \\
\hline Cotton fibers & $\begin{array}{c}\text { Heavy growth (more } \\
\text { than 60\%) } \\
\text { Light growth } \\
(10-30 \%)\end{array}$ & 5 \\
Paper mulberry fibers & $\begin{array}{c}\text { Light growth } \\
(10-30 \%)\end{array}$ & 3 \\
\hline
\end{tabular}

\section{Conclusions}

Scouring and bleaching processes were used to prepare paper mulberry fibers for spinning of cotton/paper mulberry yarns. The paper mulberry fibers were scoured with $\mathrm{NaOH}$ solution. The suitable condition for scouring of the paper mulberry fibers was $15 \%(\mathrm{w} / \mathrm{v}) \mathrm{NaOH}$ at $90^{\circ} \mathrm{C}$ for $2 \mathrm{~h}$. The removal of hemicellulose, lignin, and other impurities increased with increasing the concentration of $\mathrm{NaOH}$. Also, the optimum bleaching process of the paper mulberry fibers was $15 \% \mathrm{H}_{2} \mathrm{O}_{2}$ at $90^{\circ} \mathrm{C}$ for 90 minutes. Factors affecting the bleaching process of the paper mulberry fibers were concentration of $\mathrm{H}_{2} \mathrm{O}_{2}$, temperature, and reaction time. From the quality of paper mulberry fibers, the spinning of cotton/paper mulberry yarns was possible. The mechanical properties of produced yarns indicated that these yarns could be used in textile field. In addition, blending of the paper mulberry fibers with the cotton fibers improved the antifungal property of yarns.

\section{Competing Interests}

The authors declare that they have no competing interests.

\section{Acknowledgments}

This research is supported by a grant from the Rajamangala University of Technology Krungthep.

\section{References}

[1] P. K. Das, D. Nag, S. Debnath, and L. K. Nayak, "Machinery for extraction and traditional spinning of plant fibres," Indian Journal of Traditional Knowledge, vol. 9, no. 2, pp. 386-393, 2010.

[2] A. C. Dweck, "A review of the paper muberry," Personal Care, 2004.

[3] Z. Jin, G. Jin, S. Shao, and K. S. Katsumata, "Lignin characteristics of bast fiber and core in kenaf, bark and wood of paper mulberry and mulberry," Journal of Wood Science, vol. 58, no. 2 , pp. 144-152, 2012.

[4] N. A. Opoku-Asare and R. Yeboah, "Hand papermaking with waste fabrics and paper mulberry fibre," Online International Journal of Arts and Humanities, vol. 2, no. 3, pp. 71-82, 2013.

[5] T. Tawonpanich, P. Srinophakun, and T. Srinophakun, New Era of Cleaner Production in Mulberry Paper Industry, Chemical Engineering Department, Kasetsart University.

[6] L.-D. Lin, F.-C. Chang, C.-H. Ko, C. Y. Wang, and Y.-N. Wang, "Properties of enzyme pretreated Wikstroemia sikokiana and
Broussonetia papyrifera bast fiber pulps," BioResources, vol. 10, no. 2, pp. 3625-3637, 2015.

[7] A. Neef, P. Suebpongsang, C. Manythong, W. Tacheena, and O. Kazuo, "Can paper mulberry contribute to building sustainable rural livelihoods in northern Laos?" Southeast Asian Studies, vol. 47, no. 4, pp. 403-423, 2010.

[8] W. A. Whister and C. R. Elevitch, Broussonetia papyrifera (Paper Mulberry), Ayroforestry Net, pp. 8-9, April 2000.

[9] C. Tomasino, Fabric Preparation \& Finishing, Department of Textile Engineering Chemistry and Science, North Carolina State University, pp. 61-63, 1992.

[10] R. C. Sun, J. Tomkinson, P. L. Ma, and S. F. Liang, "Comparative study of hemicelluloses from rice straw by alkali and hydrogen peroxide treatments," Carbohydrate Polymers, vol. 42, no. 2, pp. 111-122, 2000.

[11] C. W. Dence and D. W. Reeve, Pulp Bleaching: Priciple and Practice, TAPPI Press, Atlanta, Ga, USA, 1996.

[12] J. M. Gould, "Alkaline peroxide delignification of agricultural residues to enhance enzymatic saccharification," Boitechnology and Bioengineering, vol. 26, no. 1, pp. 46-52, 1984.

[13] X.-J. Pan, Y. Sano, and T. Ito, "Atmospheric acetic acid pulping of rice straw II: behavior of ash and silica in rice straw during atmospheric acetic acid pulping and bleaching," Holzforschung, vol. 53, no. 1, pp. 49-55, 1999.

[14] Suhas, P. J. M. Carrott, and M. M. L. Ribeiro Carrott, "Ligninfrom natural adsorbent to activated carbon: a review," Bioresource Technology, vol. 98, no. 12, pp. 2301-2312, 2007.

[15] V. Srinivasan and S. Balamurugan, "Hair severity: a new yarn hariness parameter-part II," p. 7, http://www.scribd.com/ document/97265330/Hair-Severity-A-New-Yarn-HairinessParameter-Part-II. 

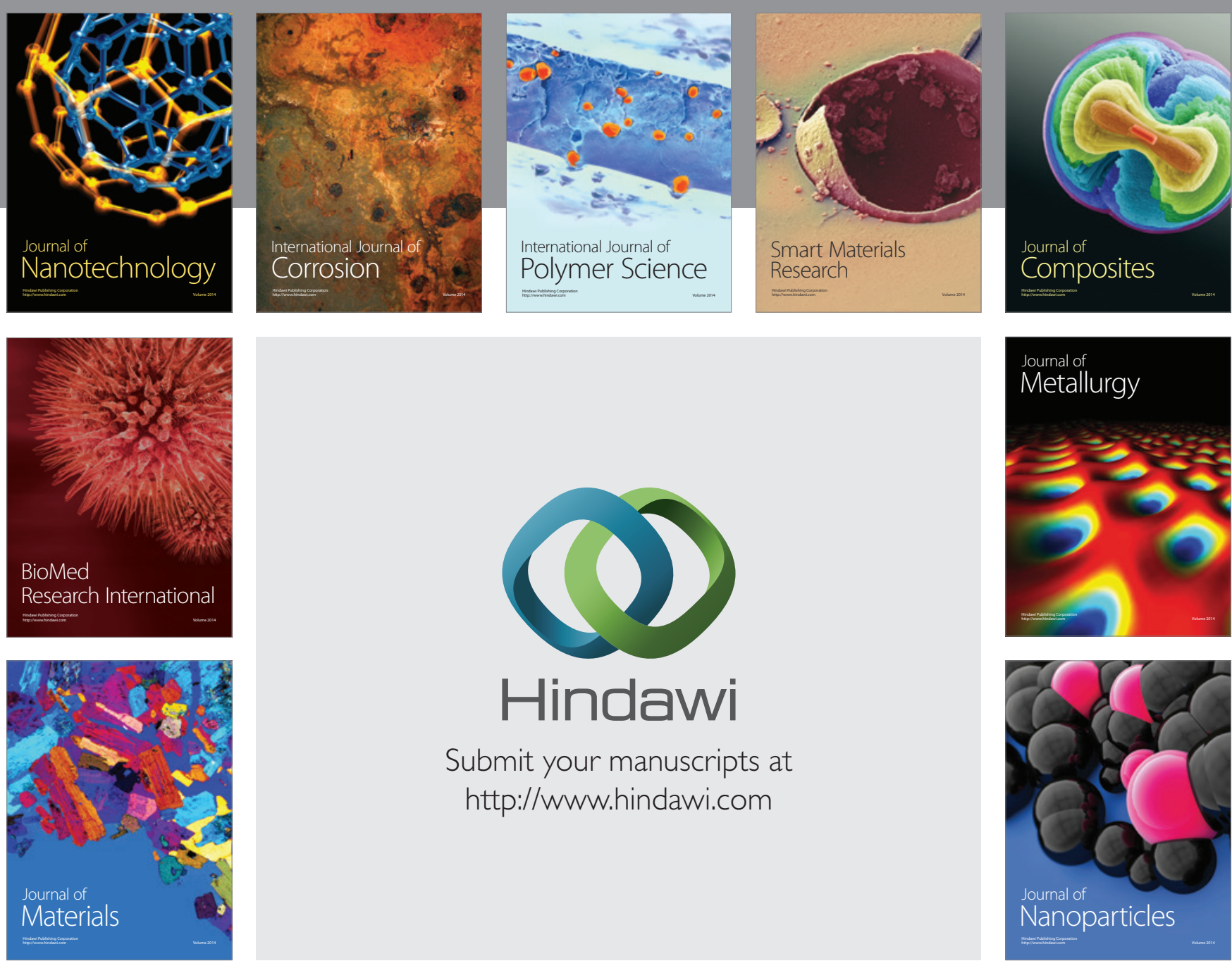

\section{Hindawi}

Submit your manuscripts at

http://www.hindawi.com

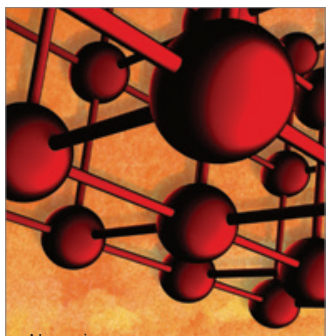

Materials Science and Engineering
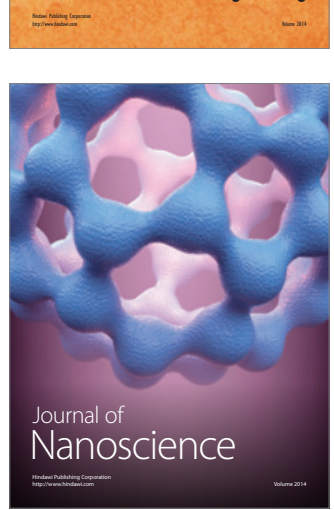
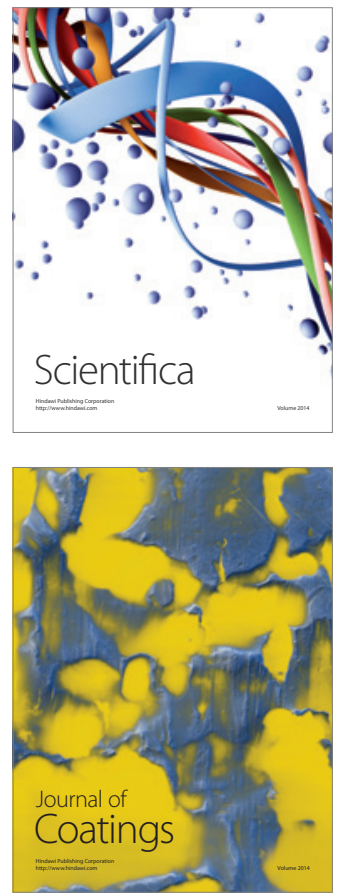
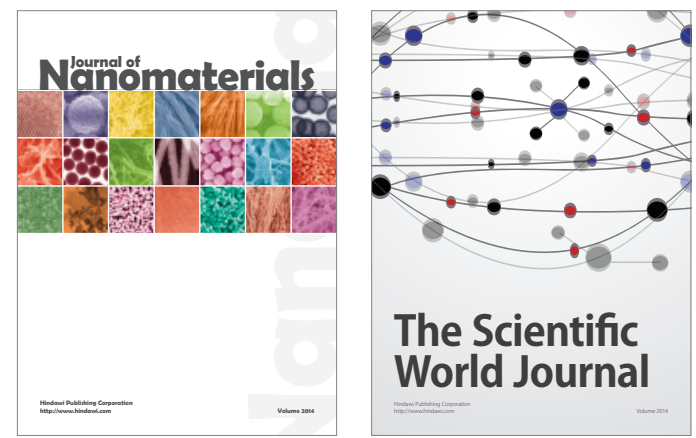

The Scientific World Journal
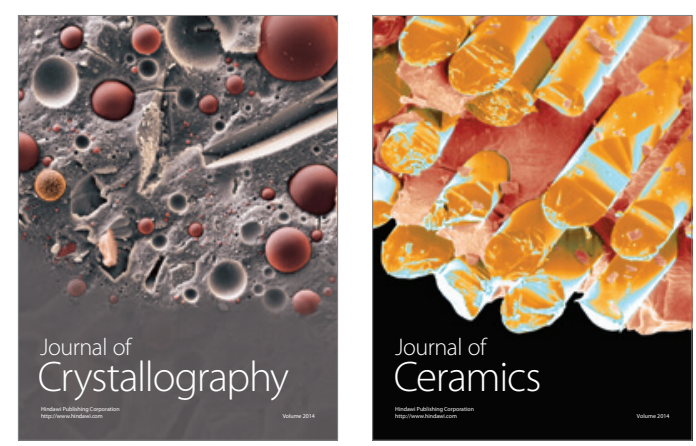
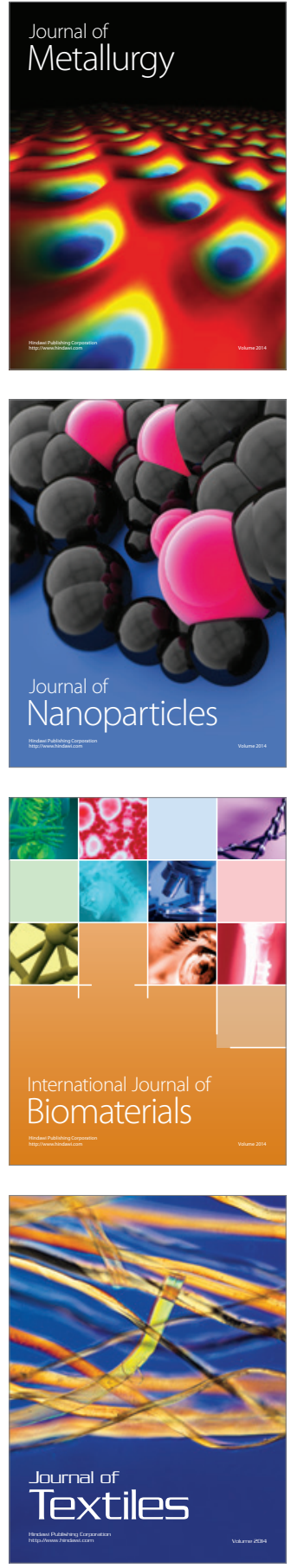